\title{
Trends in knee arthroscopy and subsequent arthroplasty in an Australian population: a retrospective cohort study
}

\author{
Ian A Harris ${ }^{1,2}$, Navdeep S Madan ${ }^{1 *}$, Justine M Naylor ${ }^{1,2}$, Shanley Chong ${ }^{1,3}$, Rajat Mittal ${ }^{1}$ and Bin B Jalaludin ${ }^{3}$
}

\begin{abstract}
Background: Knee arthroscopy is a common procedure in orthopaedic surgery. In recent times the efficacy of this procedure has been questioned with a number of randomized controlled trials demonstrating a lack of effect in the treatment of osteoarthritis. Consequently, a number of trend studies have been conducted, exploring rates of knee arthroscopy and subsequent conversion to Total Knee Arthroplasty (TKA) with varying results. Progression to TKA is seen as an indicator of lack of effect of primary knee arthroscopy.

The aim of this paper is to measure overall rates of knee arthroscopy and the proportion of these patients that undergo subsequent total knee arthroplasty (TKA) within 24 months, and to measure trends over time in an Australian population.

Methods: We conducted a retrospective cohort study of all adults undergoing a knee arthroscopy and TKA in all hospitals in New South Wales (NSW), Australia between 2000 and 2008. Datasets obtained from the Centre for Health Record Linkage (CHeReL) were analysed using negative binomial regression. Admission rates for knee arthroscopy were determined by year, age, gender and hospital status (public versus private) and readmission for TKA within 24 months was calculated.
\end{abstract}

Results: There was no significant change in the overall rate of knee arthroscopy between 2000 and 2008 (-0.68\%, $95 \% \mathrm{Cl}:-2.80$ to 1.49$)$. The rates declined in public hospitals $(-1.25 \%, 95 \% \mathrm{Cl}:-2.39$ to -0.10$)$ and remained relatively steady in private hospitals $(0.42 \%, 95 \% \mathrm{Cl}:-1.43$ to 0.60$)$. The proportion of patients 65 years or over undergoing TKA within 24 months of knee arthroscopy was $21.5 \%$. After adjusting for age and gender, there was a significant decline in rates of TKA within 24 months of knee arthroscopy for all patients (-1.70\%, 95\% Cl:-3.13 to -0.24), patients admitted to private hospitals $(-2.65 \%, 95 \% \mathrm{Cl}:-4.06$ to -1.23$)$ and patients aged $\geq 65$ years $(-3.12 \%, 95 \% \mathrm{Cl}:-5.02$ to -1.18).

Conclusions: Rates of knee arthroscopy are not increasing, and the proportion of patients requiring a TKA within 24 months of a knee replacement is decreasing in the age group most likely to have degenerative changes in the knee.

Keywords: Knee arthroscopy, Knee arthroplasty

\footnotetext{
* Correspondence: z3219646@zmail.unsw.edu.au

'South Western Sydney Clinical School, University of New South Wales,

Liverpool, NSW, Australia

Full list of author information is available at the end of the article
} 
Table 1 Procedure codes used for data extraction

\begin{tabular}{|c|c|}
\hline $49557-00$ & Arthroscopy of knee \\
\hline $49560-00$ & Arthroscopic removal of loose body of knee \\
\hline 49560-02 & Arthroscopic lateral release of knee \\
\hline 49557-01 & Arthroscopic biopsy of knee \\
\hline 49558-00 & Arthroscopic debridement of knee \\
\hline 49560-01 & Arthroscopic trimming of ligament of knee \\
\hline $49566-00$ & Arthroscopic synovectomy of knee \\
\hline 49557-02 & Arthroscopic excision of meniscal margin or plica of knee \\
\hline 49560-03 & Arthroscopic meniscectomy of knee \\
\hline 49561-00 & $\begin{array}{l}\text { Arthroscopic lateral release of knee with debridement } \\
\text { osteoplasty/chondroplasty }\end{array}$ \\
\hline 49561-01 & $\begin{array}{l}\text { Arthroscopic meniscectomy of knee with debridement, } \\
\text { osteoplasty/chondroplasty }\end{array}$ \\
\hline 49561-02 & $\begin{array}{l}\text { Arthroscopic removal of loose body with debridement, } \\
\text { osteoplasty/chondroplasty }\end{array}$ \\
\hline $49562-00$ & $\begin{array}{l}\text { Arthroscopic lateral release with chondroplasty and } \\
\text { multiple drilling or implant }\end{array}$ \\
\hline $49562-01$ & $\begin{array}{l}\text { Arthroscopic meniscectomy with chondroplasty and } \\
\text { multiple drilling or implant }\end{array}$ \\
\hline 49562-02 & $\begin{array}{l}\text { Arthroscopic removal of loose body, chondroplasty and } \\
\text { multiple drilling/implant }\end{array}$ \\
\hline 49563-00 & Arthroscopic repair of meniscus of knee \\
\hline 49558-01 & Arthroscopic chondroplasty of knee \\
\hline 49558-02 & Arthroscopic osteoplasty of knee \\
\hline 49559-00 & $\begin{array}{l}\text { Arthroscopic chondroplasty of knee with multiple drilling } \\
\text { or implant }\end{array}$ \\
\hline 4951700 & Hemiarthrosplasty of knee \\
\hline 4951800 & Total arthrosplasty of knee, unilateral \\
\hline 4951900 & Total arthrosplasty of knee, bilateral \\
\hline 4953401 & $\begin{array}{l}\text { Total Replacement arthroplasty of patellofemoral joint of } \\
\text { knee }\end{array}$ \\
\hline 4952100 & $\begin{array}{l}\text { Total arthroplasty of knee with bone graft to femur, } \\
\text { unilateral }\end{array}$ \\
\hline 4952101 & $\begin{array}{l}\text { Total arthroplasty of knee with bone graft to femur, } \\
\text { bilateral }\end{array}$ \\
\hline 4952102 & $\begin{array}{l}\text { Total arthroplasty of knee with bone graft to tibia, } \\
\text { unilateral }\end{array}$ \\
\hline 4952103 & Total arthroplasty of knee with bone graft to tibia, bilateral \\
\hline 4952400 & $\begin{array}{l}\text { Total arthroplasty of knee with bone graft to femur and } \\
\text { tibia, unilateral }\end{array}$ \\
\hline 4952401 & $\begin{array}{l}\text { Total arthroplasty of knee with bone graft to femur and } \\
\text { tibia, bilateral }\end{array}$ \\
\hline 4953000 & $\begin{array}{l}\text { Revision of total arthroplasty of knee with bone graft to } \\
\text { femur }\end{array}$ \\
\hline 4953001 & $\begin{array}{l}\text { Revision of total arthroplasty of knee with bone graft to } \\
\text { tibia }\end{array}$ \\
\hline 4953300 & $\begin{array}{l}\text { Revision of total arthroplasty of knee with bone graft to } \\
\text { femur and tibia }\end{array}$ \\
\hline 4955400 & $\begin{array}{l}\text { Revision of total arthroplasty of knee with anatomic specific } \\
\text { allograft }\end{array}$ \\
\hline 4952700 & Revision of total arthroplasty of knee \\
\hline
\end{tabular}

Table 2 Descriptive statistics for all arthroscopy patients, NSW 2000-2008

\begin{tabular}{lll}
\hline & & Number of patients (\%) \\
\hline Gender & Male & $94134(59.5 \%)$ \\
& Female & $64046(40.5 \%)$ \\
Age group (years) & $18-24$ & $12337(7.8 \%)$ \\
& $25-34$ & $20916(13.2 \%)$ \\
& $35-44$ & $28988(18.3 \%)$ \\
& $45-54$ & $36216(22.9 \%)$ \\
& $55-64$ & $33221(21.0 \%)$ \\
Hospital type & $65-74$ & $18380(11.6 \%)$ \\
& $\geq 75$ & $8122(5.1 \%)$ \\
& Public & $34929(22.1 \%)$ \\
& Private & $123251(77.9 \%)$ \\
\hline
\end{tabular}

\section{Background}

Arthroscopy is an important procedure in orthopaedic surgery, having both diagnostic and therapeutic applications. Knee arthroscopy has become the gold standard in the diagnosis of meniscal and ligamentous injury [1], and also plays a role in their management [2]. In recent times, the use of knee arthroscopy for the management of osteoarthritis has also become widespread subsequent to studies demonstrating benefit [3-6]. However, most of these studies were case series or observational in nature and thus do not provide strong evidence [7]. Other studies have questioned the use of knee arthroscopy for degenerative knee disease [8]. Nonetheless, some predictors of successful outcome emerged [9]; younger patients [10] reporting predominantly mechanical symptoms [11] with normally aligned knees [12] and short duration of symptoms [12] were more likely to benefit from arthroscopy.

Recently, three randomised controlled trials [13-15] provided high level evidence that knee arthroscopy is ineffective in the management of symptomatic osteoarthritis, including those with mechanical symptoms and meniscus tears, compared to placebo or alternative (nonoperative) treatment. In light of the disparate effectiveness of arthroscopy for different underlying conditions and age groups, a number of studies have been conducted exploring rates of knee arthroscopy for different age groups and indications [16-20]. Total Knee Arthroplasty (TKA) within 1-2 years following arthroscopy is viewed as an indicator of lack of effect of the arthroscopic procedure. Studies in other populations have reported conversion rates to TKA within two years following the procedure $[18,20]$.

This study was undertaken to describe the agestandardised rates for knee arthroscopy in an Australian population together with the conversion rate to TKA. As the utilisation rates of knee arthroscopy have also been shown to differ according to socioeconomic status [17], and as access varies between public and private 
hospitals, we also report the utilisation rates according to hospital status (private versus public).

The utilisation rates of knee arthroscopy and the rate of conversion to TKA subsequent to knee arthroscopy have not yet been described for an Australian cohort, thus, the data will serve as a useful point of reference, and will allow comparison with international rates.

\section{Methods}

Data from the New South Wales (NSW) Admitted Patient Data Collection (APDC) pertaining to arthroscopic surgery and TKA between 2000 and 2008 were obtained from the Centre for Health Record Linkage (CHeReL). The APDC contains mandatory data from all hospitals (public and private) and day-procedure centres in NSW. The Australian Classification of Health Intervention procedure codes were used to identify participants undergoing knee arthroscopy or TKA (Table 1). All arthroscopic codes were used except those for ligament reconstruction. Age-specific population estimates at 31 December of each of the years were derived from the Australian Bureau of Statistics, as these dates correspond to the mid-point of each financial year of hospitalisation.

Following data custodian and NSW Population and Health Services Research Ethics Committee approvals, the CHeReL supplied lists of de-identified specific records.

Data in the NSW Admitted Patient Data Collection prior to 1 July 2000 were incomplete, and thus the timeframe of 1st July 2000 to 31st December 2008 (the most recent available data) was chosen for this study. Data retrieved included number of knee arthroscopies and TKA by age, gender, year and hospital status (private vs. public). Data on the indications for knee arthroscopy were found to be incomplete and therefore too unreliable to report. A routine quality check by $\mathrm{CHeReL}$ using a 1000-

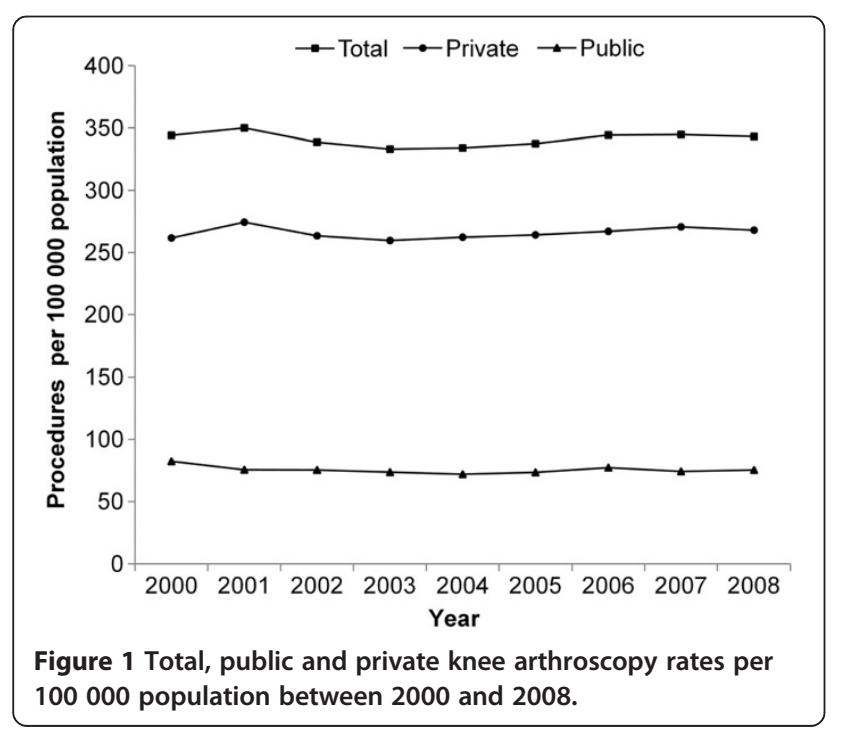

person sample from our data found a false link error rate of $4 / 1,000$ records $(0.4 \%)$.

Knee arthroscopy rates were calculated per 100000 of population aged $\geq 18$ years. The rate of TKA within 24 months of knee arthroscopy was generated by calculating the total number of TKA within 24 months of the date of initial knee arthroscopy, divided by total number of knee arthroscopies performed for each year. Negative binomial regression analyses were used to determine the percentage change in rate [21]. The main explanatory variable was year, with age and gender included as covariates.

Negative binomial regression models were applied to determine the percentage change in rate and to accommodate for over-dispersion in the data, with the log of NSW population used as an offset to control for the population changes over time.

\section{Results}

Knee arthroscopy rates by year and hospital status

Descriptive statistics for all patients undergoing knee arthroscopy are provided in Table 2. The rate of knee arthroscopy was unchanged over the period studied: from 344.1 per 100,000 people in 2000 to 343.3 per 100,000 people in 2008 (change in rate: $-0.68 \%, 95 \%$ CI: $-2.80-1.49$ ) (Figure 1). In public hospitals, there was a significant decline from 82.3 per 100000 people in 2000 to 75.3 per 100000 people in 2008 (change in rate: $-1.25 \%$, 95\% CI: $-2.39--0.10$ ); in private hospitals, the rate changed from 261.8 per 100000 people in 2000 to 268.0 per 100000 people in 2008 (change in rate: $-0.42 \%, 95 \%$ CI: $-1.43-0.60$ ). The ratio of the rate of private knee arthroscopies to public knee arthroscopies in NSW in 2008 was 3.6:1 compared to 3.2:1 in 2000. The total number of knee arthroscopies (not adjusted for population change)

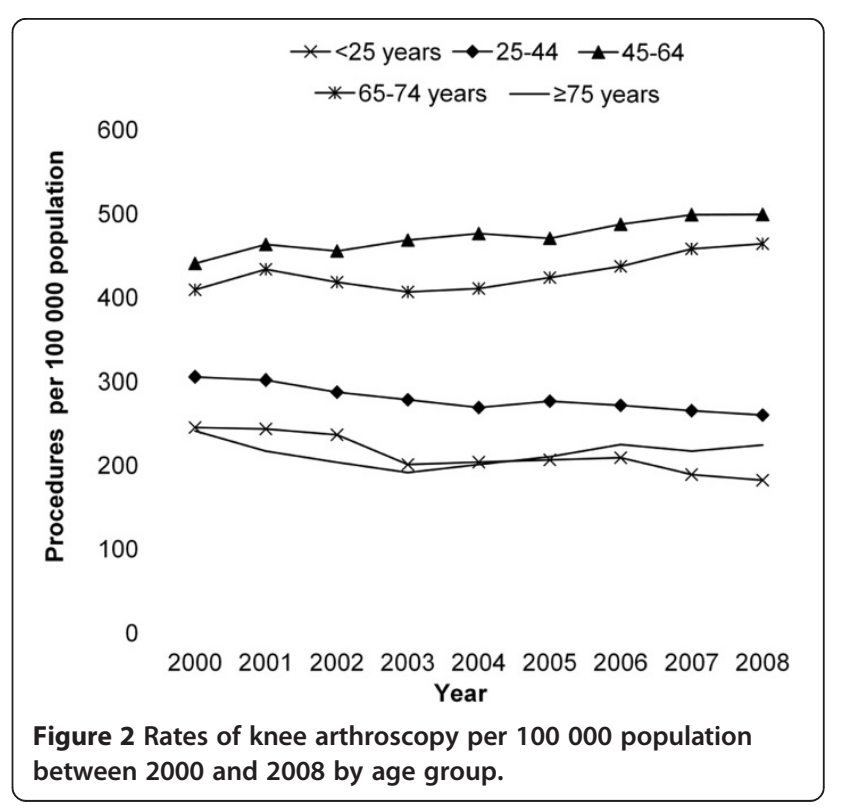


Table 3 Changes in knee arthroscopy rate between 2000 and 2008 for each age group

\begin{tabular}{lccccccc}
\hline Age group (years) & $<\mathbf{2 5}$ & $\mathbf{2 5 - 3 4}$ & $\mathbf{3 5 - 4 4}$ & $\mathbf{4 5 - 5 4}$ & $\mathbf{5 5 - 6 4}$ & $\mathbf{6 5 - 7 4}$ & $\geq \mathbf{7 5}$ \\
\hline Rate change & $-4.12 \%$ & $-2.96 \%$ & $-0.71 \%$ & $0.94 \%$ & $1.89 \%$ & $1.01 \%$ & $-1.02 \%$ \\
$\mathbf{9 5 \%} \mathrm{Cl}$ & $-9.08-1.11$ & $-7.96-2.31$ & $-6.28-5.17$ & $-5.10-7.37$ & $-3.69-7.78$ & $-2.52-4.65$ & $-5.89-4.09$ \\
\hline
\end{tabular}

increased by $1.1 \%(\mathrm{p}=0.007)$ in public hospitals and by $13.0 \%(\mathrm{p}<0.001)$ in private hospitals between 2000 and 2008.

\section{Knee arthroscopy rates by age group}

The rate of knee arthroscopy was also examined by age across the study period (Figure 2). After adjusting for sex, there was no significant change in rates of knee arthroscopy over time by age group (Table 3 ).

\section{Rates of readmission for primary TKA within 24 months of knee arthroscopy}

The rates of primary TKA within 24 months following knee arthroscopy for years 2000 to 2006 are shown in Table 4. After adjusting for age and sex, there was a significant decline in the overall rate of readmission for TKA (change in rate: $-1.70 \%, 95 \%$ CI: $-3.13--0.24$ ), readmission rates in private hospitals (change in rate: $-2.65 \%$, 95\% CI: $-4.06--1.23$ ) and in patients aged $\geq 65$ years (change in rate: $-3.12 \%, 95 \%$ CI: $-5.02--1.18$ ). In public patients the rates of conversion remained relatively steady (change in rate: $-0.26 \%, 95 \% \mathrm{CI}:-2.33-1.85$ ). The rate of conversion to TKA was not calculated after 2006 as 24 month follow-up data was not available after that time.

\section{Discussion}

The rate of knee arthroscopy in NSW (334.0 per 100 000 in 2004) is higher than rates reported for England (<150 per 100000 population in 2004) and also higher than those found in Canada ( $<200$ per 100000 population in 2004) [17]. However, the rate is lower than has been reported in the USA (404 per 100000 population over a similar period) [22].

Over the 7.5-year period studied, there was a significant decline in the rates of knee arthroscopy in public hospitals whilst the rate remained relatively unchanged in private hospitals, and overall, the rate was higher in private hospitals. This difference may be due to a lack of access to the public sector, forcing uninsured patients into the private sector. Alternatively, differing thresholds for surgery may exist between private and public patients. Financial reimbursement has also been shown to influence surgical decision-making and the greater rates of knee arthroscopy in private hospitals may be related to greater financial incentives for surgeons [23]. The steady rates of knee arthroscopy in private hospitals may be explained by the increasing rate of private health insurance which has occurred in recent times; the rate of private insurance increased $2 \%$ (from 52\% to 54\%) for NSW between 2000 and 2008 [24,25].

We found a lack of significant change in rates of knee arthroscopy over time. Data from Canada and England have shown that the utilisation of knee arthroscopy for the treatment of osteoarthritis decreased between 1993 and 2004, but the overall rates of arthroscopy increased in England, and remained steady in Ontario [17]. Similarly, US data comparing 2006 to 1996 found an increase in the overall rate of knee arthroscopy, but a decrease in the rate for osteoarthritis [22]. The decreasing rate of knee arthroscopy was also noted in a review of case logs

Table 4 Rate of readmission for primary TKA within 24 months of knee arthroscopy

\begin{tabular}{llllllllll}
\hline & & $\mathbf{2 0 0 0}$ & $\mathbf{2 0 0 1}$ & $\mathbf{2 0 0 2}$ & $\mathbf{2 0 0 3}$ & $\mathbf{2 0 0 4}$ & $\mathbf{2 0 0 5}$ & $\mathbf{2 0 0 6}$ & Total \\
\hline All ages & TKA within 24 m of arthroscopy & 1244 & 1361 & 1351 & 1313 & 1234 & 1246 & 1361 & 9110 \\
& Total arthroscopies & 16942 & 17469 & 17083 & 16947 & 17141 & 17478 & 18055 & 121115 \\
& Proportion of total cases & $7.3 \%$ & $7.8 \%$ & $7.9 \%$ & $7.8 \%$ & $7.2 \%$ & $7.1 \%$ & $7.5 \%$ & $7.5 \%$ \\
All ages (Private) & TKA within 24 m of arthroscopy & 966 & 1050 & 1013 & 1014 & 942 & 923 & 1030 & 6938 \\
& Total arthroscopies & 12892 & 13703 & 13287 & 13208 & 13457 & 13681 & 14006 & 94234 \\
& Proportion of total cases & $7.5 \%$ & $7.7 \%$ & $7.6 \%$ & $7.7 \%$ & $7.0 \%$ & $6.8 \%$ & $7.4 \%$ & $7.4 \%$ \\
\multirow{3}{*}{ All ages (Public) } & TKA within 24 m of arthroscopy & 278 & 311 & 338 & 299 & 292 & 323 & 331 & 2172 \\
& Total arthroscopies & 4050 & 3766 & 3796 & 3739 & 3684 & 3797 & 4049 & 26881 \\
& Proportion of total cases & $6.9 \%$ & $8.3 \%$ & $8.9 \%$ & $8.0 \%$ & $7.9 \%$ & $8.5 \%$ & $8.2 \%$ & $8.1 \%$ \\
& TKA within 24 m of arthroscopy & 656 & 689 & 614 & 604 & 564 & 551 & 614 & 4292 \\
& Total arthroscopies & 2832 & 2891 & 2790 & 2707 & 2799 & 2904 & 3049 & 19972 \\
& Proportion of total cases & $23.2 \%$ & $23.8 \%$ & $22.0 \%$ & $22.3 \%$ & $20.2 \%$ & $19.0 \%$ & $20.1 \%$ & $21.5 \%$ \\
\hline
\end{tabular}


for the American Board of Orthopaedic Surgery [26]. Another Australian study found an overall reduction of elective knee arthroscopy procedures in Victorian hospitals from 2000-2009 [27].

The rate of TKA within two years of arthroscopy for patients over 64 years of age is higher than figures reported elsewhere. Raaijmaakers et al. [18] found that $17.4 \%$ of patients aged 65 years or older required a TKA within 24 months in one hospital in Belgium. In a Canadian study of patients over the age of 50 years at the time of arthroscopy, 9.2\% received a TKA within one year and $18.4 \%$ within three years [19]. A similar study in Scotland found that over $15.3 \%$ of patients over 60 years of age undergoing a knee arthroscopy proceeded to TKA in two years and those regions with the highest rates of arthroscopy also had the highest rates of conversion to TKA within two years [20].

The rate of conversion to TKA within 24 months observed in the over 64 year age group may indicate a lack of effectiveness of arthroscopy in older patients [13]. The decline in the conversion rate of arthroscopy to TKA over the study period may reflect better patient selection, improvements in adjunctive therapy, or longer waiting times for TKA.

A potential limitation of this study is that it relied on administrative datasets. Administrative datasets may comprise incomplete patient data and coding errors. There is also a potential for selection bias due to missing procedure codes. We were unable to obtain the rates of missing procedure codes from the data custodian. Furthermore, the affected side is not reported in these datasets, thus, it is possible that some patients may have had an arthroscopy followed by TKA on the opposite limb. To address this limitation, we used a convenience sample from two of the institutions, covering the same time period as the main study. Of 42 retrieved cases of knee arthroscopies followed by total knee replacements, two cases involved contralateral knees, the remaining cases were ipsilateral. Therefore our rate of conversion to TKA is likely to be an overestimation of the true rate. The indication for knee arthroscopy may affect the likelihood of conversion to TKA, however the indications for knee arthroscopy were poorly reported, thus we were unable to provide such data.

\section{Conclusions}

This study shows decreasing rates of knee arthroscopy in public hospitals and relatively steady rates in private hospitals in an Australian population across a 9-year period. The rates of conversion to TKA following knee arthroscopy were higher than those reported elsewhere, but were decreasing over time.

\footnotetext{
Abbreviations

CHeReL: The Centre for Health Record Linkage; NSW: New South Wales;

TKA: Total knee arthroplasty.
}

\section{Competing interests}

The authors have no competing interests (financial or non-financial) to declare.

\section{Authors' contributions}

$\mathrm{IAH}$ conceived of the study, ensuring the study abided by initial objectives at all points and helped draft the final manuscript. NSM applied for ethics approval, performed data analyses and helped draft the manuscript. JMN helped with ethics approval, performed data analyses and helped draft the manuscript. SC performed necessary statistical analyses and helped draft the methodology section. RM helped with ethics approval, performed data analyses and helped draft the manuscript. BBJ helped with data analyses and helped draft the manuscript. All authors read and approved the final manuscript.

\section{Author details}

'South Western Sydney Clinical School, University of New South Wales, Liverpool, NSW, Australia. ${ }^{2}$ Orthopaedic Department, Liverpool Hospital, Liverpool, NSW, Australia. ${ }^{3}$ Centre for Research, Evidence Management and Surveillance, Liverpool, NSW, Australia.

Received: 5 October 2012 Accepted: 19 April 2013

Published: 23 April 2013

\section{References}

1. Spahn M, Klinger M: How valid is the arthroscopic diagnosis of cartilage lesions? Results of an opinion survey among highly experienced arthroscopic surgeons. Arch Orthop Trauma Surg 2009, 129:1117-1121.

2. Simpson DA, Thomas NP, Aichroth PM: Open and closed meniscectomy: a comparative analysis. J Bone Joint Surg Br 1986, 68:301-304.

3. Sprague NF: Arthroscopic debridement for degenerative knee joint disease. Clin Orthop Relat Res 1981, 160:118-123.

4. Rand JA: Role of arthroscopy in osteoarthritis of the knee. Arthroscopy 1991, 7:358-363.

5. Baumgaertner MR, Cannon WD Jr, Vittori JM, Schmidt ES, Maurer RC: Arthroscopic debridement of the arthritic knee. Clin Orthop Relat Res 1990, 253:197-202.

6. McGinley BJ, Cushner FD, Scott WN: Debridement arthroscopy. 10-year follow up. Clin Orthop Relat Res 1999, 367:190-194.

7. Laupattarakasem W, Laopaiboon M, Laupattarakasem P, Sumananont C: Arthroscopic debridement for knee osteoarthritis. Cochrane Database Syst Rev 2008, 1, CD005118

8. Gibson JN, White MD, Chapman VM, Strachan RK: Arthroscopic lavage and debridement for osteoarthritis of the knee. J Bone Joint Surg Br 1992, 74:534-537.

9. David T, Gambardella R: Arthroscopic debridement of the arthritic knee: indications and results. Curr Opin Orthop 2000, 11:9-13.

10. Aicroth PM, Patel DV, Moyes ST: A prospective review of arthroscopic debridement for degenerative joint disease of the knee. Int Orthop 1999, 15:351-355.

11. Dervin GF, Stiell IG, Rody K, Grabowski J: Effect of arthroscopic debridement for osteoarthritis of the knee on health-related quality of life. J Bone Joint Surg Am 2003, 85:10-19.

12. Fond J, Rodin D, Ahmad S, Nirschl RP: Arthroscopic debridement for the treatment of osteoarthritis of the knee: 2- and 5-year results. Arthroscopy 2002, 18:829-834.

13. Moseley JB, O'Malley K, Petersen NJ, Menke TJ, Brody BA, Kuykendall DH, Hollingsworth JC, Ashton CM, Wray NP: A controlled trial of arthroscopic surgery for osteoarthritis of the knee. New Engl J Med 2002, 347:81-88.

14. Kirkley A, Birmingham TB, Litchfield RB, Giffin JR, Willits KR, Wong CJ, Feagan BG, Donner A, Griffin SH, D'Ascanio LM, Pope JE, Fowler PJ: A randomized trial of arthroscopic surgery for osteoarthritis of the knee. New Engl J Med 2009, 359:1097-1107.

15. Herrlin $S$, Hallander M, Wange $P$, Weidenhielm L, Werner S: Arthroscopic of conservative treatment of degenerative medial meniscus tears: a prospective randomised trial. Knee Surg Sports Traumatol Arthosc 2007, 15:393-401.

16. Johanson NA, Kleinbart FA, Cerynik DL, Brey JM, Ong KL, Kurtz SM: Temporal relationship between knee arthroscopy and arthroplasty: a quality measure for joint care? J Arthroplasty 2011, 26:187-191. 
17. Hawker G, Guan J, Judge A, Dieppe P: Knee arthroscopy in England and Ontario: patterns of use, changes over time, and relationship to total knee replacement. J Bone Joint Surg Am 2008, 90:2337-2345.

18. Raaijmaakers M, Vanlauwe J, Vandenneucker H, Dujardin J, Bellemans J: Arthroscopy of the knee in elderly patients: cartilage lesions and their influence on short term outcome. A retrospective followup of 183 patients. Acta Orthop Belg 2010, 76:79-85.

19. Wai EK, Kreder HJ, Williams Jl: Arthroscopic debridement of the knee for osteoarthritis in patients fifty years of age or older: utilization and outcomes in the Province of Ontario. J Bone Joint Surg Am 2002, 84:17-22.

20. Dearing J, Brenkel I: Incidence of knee arthroscopy in patients over 60 years of age in Scotland. Surgeon 2010, 8:144-150.

21. McCullagh P, Nelder JA: Generalized linear models. 2nd edition. London: Chapman and Hall; 1989.

22. Kim S, Bosque J, Meehan JP, Jamali A, Marder R: Increase in outpatient knee arthroscopy in the United States: a comparison of national surveys of ambulatory surgery, 1996 and 2006. J Bone Joint Surg Am 2011, 93:994-1000.

23. Lingard EA, Berven S, Katz JN: Management and care of patients undergoing total knee arthroplasty: variations across different health care settings. Arthrit Care Res 2000, 13:129-136.

24. Australian Bureau of Statistics: NSW State and Regional Indicators 2008: Private Health Insurance Coverage NSW and ACT. Canberra: Australian Bureau of Statistics; 2009.

25. Australian Bureau of Statistics: NSW State and Regional Indicators 2010: Private Health Insurance Coverage NSW and ACT. Canberra: Australian Bureau of Statistics; 2010.

26. Potts A, Harrast JJ, Harner CD, Miniaci A, Jones MH: Practice patterns for arthroscopy of osteoarthritis of the knee in the United States. Am J Sports Med 2012, 40:1247-1251.

27. Bohensky MA, Sundarajan V, Andrianopoulos N, de Steiger RN, Bucknill A, Kondogiannis CM, McColl G, Brand CA: Trends in elective knee arthroscopies in a population-based cohort, 2000-2009. Med J Aust 2012, 197:399-403.

doi:10.1186/1471-2474-14-143

Cite this article as: Harris et al:: Trends in knee arthroscopy and

subsequent arthroplasty in an Australian population: a retrospective cohort study. BMC Musculoskeletal Disorders 2013 14:143.

\section{Submit your next manuscript to BioMed Central and take full advantage of:}

- Convenient online submission

- Thorough peer review

- No space constraints or color figure charges

- Immediate publication on acceptance

- Inclusion in PubMed, CAS, Scopus and Google Scholar

- Research which is freely available for redistribution 